\title{
The Effects of Therapeutic Climbing on Shoulder Muscle Activity according to the Inclination of the Climbing Wall
}

\author{
Eun-Jeong Kim, Se-Hun Kim \\ Department of Physical Therapy, College of Health Science, Dongshin University, Naju, Korea
}

Purpose: Therapeutic climbing has become very popular today, with it being reported as a new method for preventing and treating orthopedic trauma to the shoulder joint. However, objective studies on its effects on the musculoskeletal system are still lacking. The objective of the present study was to investigate the effects of wall inclination during therapeutic climbing on the muscle activity around the shoulder joint.

Methods: In this study, the participants performed movements at three different inclination angles of $0^{\circ},+15^{\circ}$, and $-15^{\circ}$. sEMG was performed to measure the activities of five different muscles around the shoulder joint (biceps brachii, serratus anterior, upper trapezius, middle trapezius, and lower trapezius muscles).

Results: Biceps brachii muscle showed a significant increase at $-15^{\circ}$, as compared to $0^{\circ}(p<0.01)$, and the serratus anterior also showed a significant increase at $-15^{\circ}$, as compared to $0^{\circ}(p<0.05)$. Moreover, the middle and lower trapezius muscles also showed a significant increase at $-15^{\circ}$, as compared to $0^{\circ}(\mathrm{p}<0.001)$. Compared to $0^{\circ}$, all muscles showed decreased values at $15^{\circ}$, but the differences were not statistically significant $(p>0.05)$.

Conclusion: Therapeutic climbing may be a new therapeutic approach that can increase muscle strength and coordination in the sensory nervous system, since it can be used as a tool that promotes active movement by altering wall inclination and causing the user to generate movements according to the existing situation.

Keywords: Therapeutic climbing, Shoulder muscle activity, Inclination

\section{INTRODUCTION}

Sports climbing is a whole-body exercise that requires the use of both hands and both legs, where the exercise effect varies depending on how the hand and foot holds are held and for how long. It can build muscle strength, muscle endurance, cardiopulmonary endurance, and flexibility, and thus, it can be used to train body coordination, speed, agility, balance, and quickness. ${ }^{1}$

Therapeutic climbing that utilizes these elements was first introduced in the early 2000s by Dr. Rene Kittel of Germany through the Potsdam model. In recent times, this novel therapeutic approach, which uses the motions involved in artificial wall climbing, has been applied in the field of physical therapy to treat not only orthopedic disorders, but also trauma, neurologic, and mental disorders. ${ }^{2}$

Received May 8, 2018 Revised Jun 12, 2018

Accepted Jun 19, 2018

Corresponding author Se-Hun Kim

E-mail ptsehun@gmail.com
Therapeutic climbing has the characteristic ability of simultaneously stimulating muscle strength, agility, and coordination, and as a result, there is an increasing trend of its use in treating patients with orthopedic disorders and injuries. ${ }^{3}$ The shoulder joint has the largest range of motion in the human body and is most susceptible to dislocation and subluxation, where chronic shoulder pain represents a typical musculoskeletal disorder that can cause symptoms such as shoulder pain, limited range of motion, or functional impairments. $^{4,5}$

Patients with shoulder impingement syndrome or rotator cuff injury showed limited scapular upward rotation, posterior tilt, and internal rotation of the shoulder. Patients incapable of scapular upward rotation showed greater limitations in internal rotation of the shoulder, which created greater shoulder joint instability. ${ }^{6}$ Move-

Copylight (C2018 The Korea Society of Physical Therapy

This is an Open Access article distribute under the terms of the Creative Commons Attribution Non-commercial License (Http:// creativecommons.org/license/by-nc/4.o.) which permits unrestricted non-commercial use, distribution, and reproduction in any medium, provided the original work is properly cited. 
ment of the shoulder joint is controlled by the force couple involving the upper trapezius, lower trapezius, and serratus anterior to generate upward scapular rotation supraduction. However, when this force collapses, kinetic changes occur in the scapula, resulting in abnormal scapular movement and narrowing of the subacromial space that can cause impingement syndrome, affecting the muscle activities in the head and neck areas. ${ }^{78}$

The first step in shoulder rehabilitation must be comprised of exercise that can normalize the activity of force couple of the scapular muscles and return the scapula to its normal position at rest. Based on such rationale, exercise that can reduce the activity level of the upper trapezius and induce activation of the middle trapezius, lower trapezius, and serratus anterior should be selected for shoulder stability exercise. ${ }^{9-11}$

To effectively apply rehabilitation training, it is necessary to have a training method that can increase the exercise effect and targets muscle activation. The level of difficulty for exercises can be increased or decreased by altering the intensity of the exercise. The level of difficultly of therapeutic climbing can be adjusted by altering the positions of the hand and foot holds, point of body contact fixed on the wall, and wall inclination. ${ }^{12}$ However, studies on chang- es in such difficulty levels of training have been limited to static therapeutic climbing exercise for the leg and trunk muscles. ${ }^{13,14}$

Moreover, most studies have examined the effects of therapeutic climbing training on psychological effects and improvement effects on fitness and functional performance, while analyses on changes in muscle activities at specific angles based on wall inclination during climbing are still lacking. Accordingly, the objective of the present study was to conduct a comparative analysis on the changes in muscle activities of biceps brachii, serratus anterior, upper trapezius, middle trapezius, and lower trapezius muscles based on wall inclination during therapeutic climbing.

\section{METHODS}

\section{Participants}

The present study included 30 men. No participants had any physical defect that would affect the study results, had any pain related to musculoskeletal disorders in the past six months, or had any visual or hearing impairment that would interfere with their ability to adjust the wall inclination. Prior to the study, the participants received sufficient explanation on the objective and methods of the study,
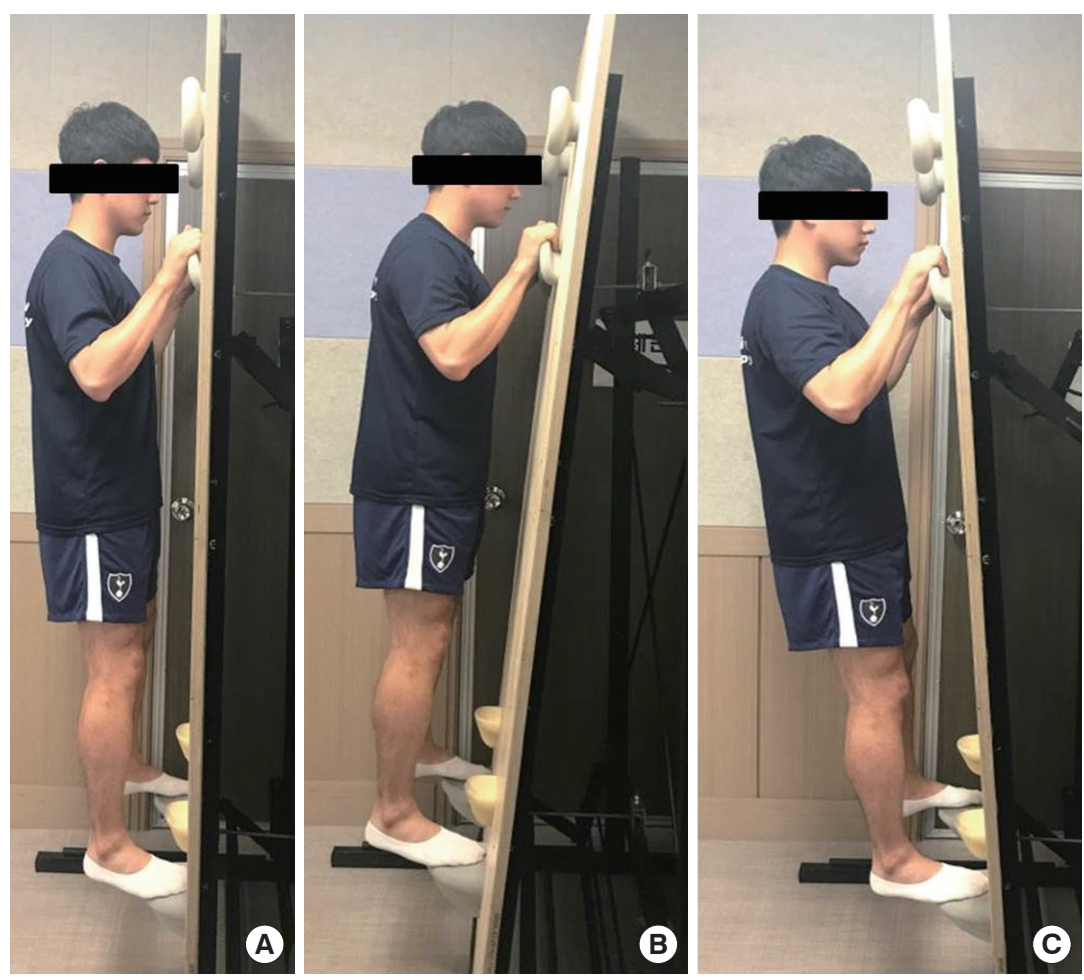

Figure 1. The climbing wall inclination angles $\left(a .0^{\circ}\right.$, b. $+15^{\circ}$, c. $\left.-15^{\circ}\right)$. 
and those who voluntarily gave their consent to participate in the experiment were included.

\section{Methods}

For observation of muscle activities around the shoulder area during climbing based on different wall inclination, the climbing wall inclination angles were set to $0^{\circ}$ (vertical), $15^{\circ}$ (positive inclination), and $-15^{\circ}$ (negative inclination) (Figure 1). The movements performed during therapeutic climbing consisted of diagonal climbing with unilateral adduction and external rotation, as presented by Rene Kittel, ${ }^{15}$ and the movements were performed with the inclination already adjusted (Figure 2).

\section{Muscle activity measurement}

BTS FreeEMG 1000 system (Bioengineering, Inc., Italy) was used to measure muscle activity in the biceps brachii, serratus anterior, and upper, middle, and lower trapezius muscles. To reduce skin resis-

Table 1. Muscle attachment

\begin{tabular}{ll}
\hline Muscle & \multicolumn{1}{c}{ Attachment } \\
\hline Biceps brachii & Middle area of biceps brachii \\
Serratus anterior & Below the armpits, front of latissimus dorsi muscle, 4-6th ribs \\
Upper trapezius & Midpoint between C7 and posterior acromion \\
Middle trapezius & $\begin{array}{l}\text { Middle of spinous scapula and spinous process on the same } \\
\text { horizontal plane }\end{array}$ \\
Lower trapezius & $\begin{array}{l}\text { Approximately } 3 \mathrm{~cm} \text { lateral to spinous process located on } \\
\text { the same line as the scapula with external rotation of the } \\
\text { shoulder joint }\end{array}$ \\
\hline
\end{tabular}
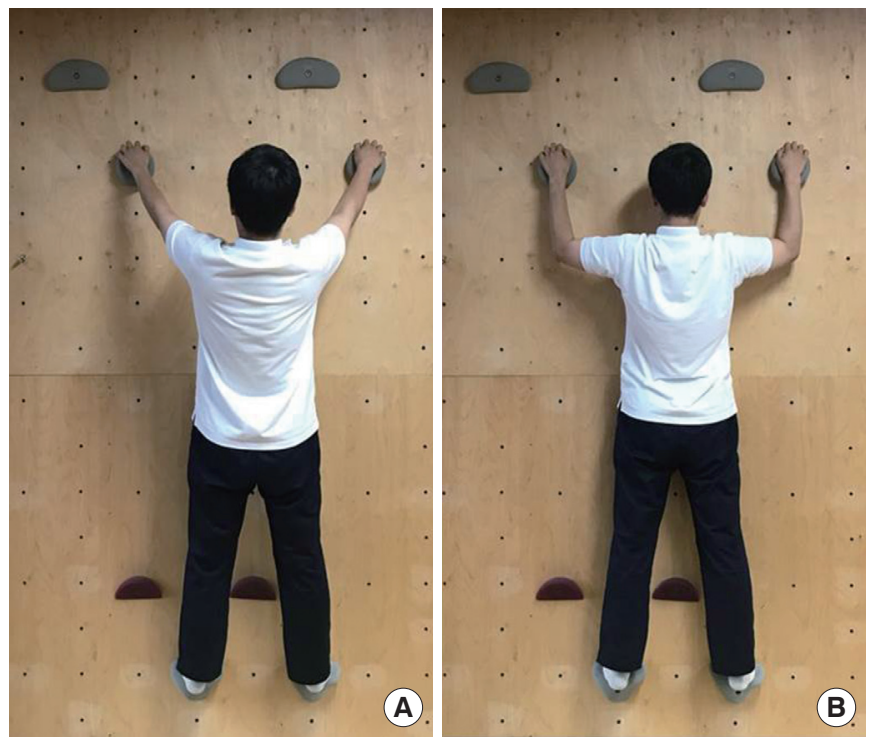

tance against surface-electromyography (sEMG) signals, hair on the attachment area was removed and the area was scrubbed 2-4 times with an abrasive to remove any dead skin, after which, rubbing alcohol was used to clean the skin (Table 1). ${ }^{16}$

The collected data were sent over a wireless LAN communication system ( $\mathrm{WiFi}$ ) to a wireless router connected to a computer by LAN cable and the automatically-displayed values of the original data from MYOLAB (software, BTS Co., Italy) were used in pocket EMG.

Each measurement lasted 12 seconds, but the measured values from only 10 seconds were used by excluding the first and last second. Three repeated measurements were taken, and the mean measured values were used. Here, for the reference values for standardization, three repeated measurements were taken while maintaining maximum muscle activity in each muscle for 5 seconds during maximal voluntary isometric contraction (MVIC) while manual resistance was applied. After processing the 5-second data by RMS, the mean EMG signal over 3 seconds was used as 100\% MVIC, after excluding the first and last second. ${ }^{17}$

During the MVIC measurement, the participants performed the movements while in the standing position with their legs spread shoulder-width apart and their palms pointing forward. The measurements were taken after training the participants to prevent compensation while performing the movements. The movements were performed with manual resistance applied in the opposite direction of the movement by each muscle. The movements involved
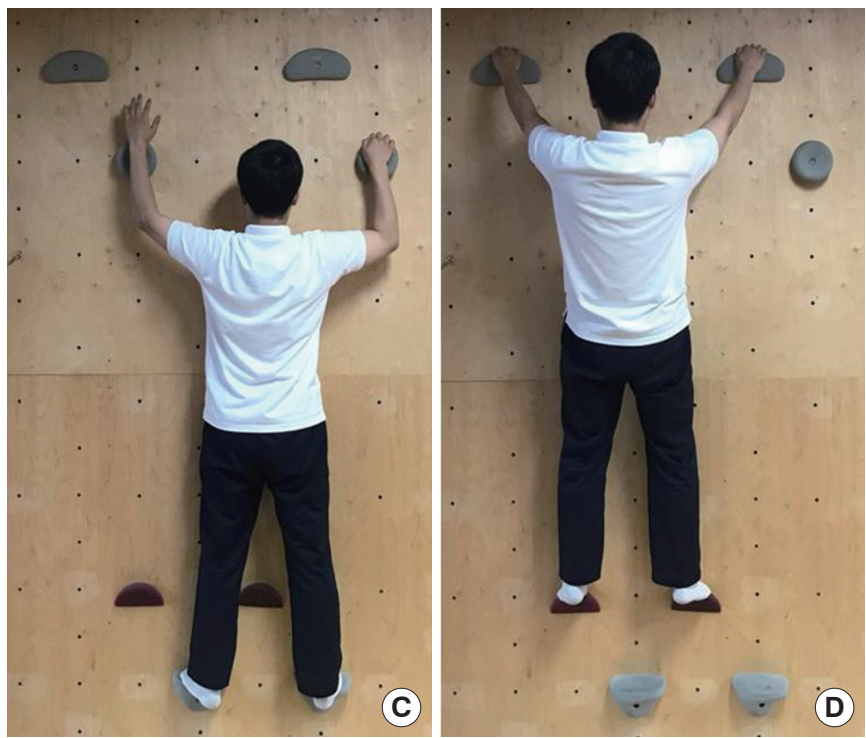

Figure 2. Movement of therapeutic climbing(diagonal climbing with unilateral adduction and external rotation). 
$90^{\circ}$ elbow flexion with forearm supination on a bench for the biceps brachii muscle, internal rotation, together with scapular upward rotation after $90^{\circ}$ abduction and external rotation of the shoulder for the serratus anterior muscle; scapular elevation after posterolateral extension of the neck for the upper trapezius muscle; and scapular descent with the shoulder flexed above the head for the middle and lower trapezius muscles. ${ }^{18}$

\section{Statistical methods}

The experimental data were analyzed using SPSS ver. 12.0 for windows (SPSS Inc., Chicago, IL, USA). All data were tested for normal distribution using the Shapiro-Wilk test, while descriptive statistics were used for general characteristics of the participants. For comparisons of differences between the groups, significance testing was performed using one-way ANOVA. A Post-hoc test was performed using the Tukey's multiple range test. For testing of statistical significance, the significance level was set to $\alpha=0.05$.

\section{RESULTS}

\section{General characteristics of the participants}

The participants in the present study consisted of 30 men, whose mean age, height, and weight were $26.4 \pm 6.7$ years, $175.7 \pm 7.5 \mathrm{~cm}$, and $72.7 \pm 12.4 \mathrm{~kg}$, respectively (Table 2 ).

\section{Significance testing by each angle for changes in muscle activity}

Assessment of the changes in muscle activity showed significant

Table 2. General characteristics of subjects

$(n=30)$

\begin{tabular}{ccc}
\hline Age $(\mathrm{yr})$ & Height $(\mathrm{cm})$ & Weight $(\mathrm{kg})$ \\
\hline $26.4 \pm 6.7$ & $175.7 \pm 7.5$ & $72.7 \pm 12.4$ \\
\hline
\end{tabular}

Values are presented as mean \pm standard deviation. differences in the biceps brachii, middle trapezius, and lower trapezius muscles $(\mathrm{p}<0.01)$, and the serratus anterior muscle also showed a significant difference $(\mathrm{p}<0.05)$. Post-hoc test results showed that the biceps brachii muscle showed a significant increase at $-15^{\circ}$, as compared to $0^{\circ}(\mathrm{p}<0.01)$, and the serratus anterior also showed a significant increase at $-15^{\circ}$, as compared to $0^{\circ}(\mathrm{p}<0.05)$. Moreover, the middle and lower trapezius muscles also showed a significant increase at $-15^{\circ}$, as compared to $0^{\circ}(\mathrm{p}<0.001)$. Compared to $0^{\circ}$, all muscles showed decreased values at $15^{\circ}$, but the differences were not statistically significant $(\mathrm{p}>0.05)$ (Table 3 ).

\section{DISCUSSION}

Pain in the shoulder joint can occur from musculoskeletal disorders caused by improper movement and overuse during physical activities, and shoulder pain represents the second most-common pain after lower back pain. ${ }^{19}$ Physical therapy interventions used in clinical practice to resolve shoulder pain includes approaches such as exercise therapy, self-stretching exercise, proprioceptive neuromuscular stimulation, group and home exercise programs and taping therapy. ${ }^{19-21}$

Compared to other rehabilitation exercise, therapeutic climbing requires a greater level of active participation by the patient, which has been reported to be effective in increasing muscle strength, mobility, and whole-body coordination..$^{22}$ Moreover, therapeutic climbing has become very popular today, with it being reported as a new method for preventing and treating orthopedic trauma to the shoulder joint. However, objective studies on its effects on the musculoskeletal system are still lacking. ${ }^{23,24}$

The objective of the present study was to investigate the effects of wall inclination during therapeutic climbing on the muscle activity around the shoulder joint. In this study, the participants performed

Table 3. A comparison of muscle activity in each group (\%MVIC)

\begin{tabular}{|c|c|c|c|c|}
\hline & $0^{\circ}$ & $+15^{\circ}$ & $-15^{\circ}$ & $p$ \\
\hline Biceps brachii & $6.83 \pm 4.15$ & $5.76 \pm 3.84$ & $13.75 \pm 7.43^{* *}$ & 0.008 \\
\hline Serratus anterior & $4.58 \pm 3.41$ & $3.15 \pm 2.82$ & $8.13 \pm 5.37^{*}$ & 0.025 \\
\hline Upper trapezius & $2.44 \pm 0.86$ & $2.03 \pm 0.57$ & $5.67 \pm 2.35$ & 0.970 \\
\hline Middle trapezius & $8.72 \pm 6.71$ & $6.34 \pm 3.22$ & $21.69 \pm 12.83^{* \star *}$ & 0.003 \\
\hline Lower trapezius & $16.73 \pm 10.62$ & $14.68 \pm 8.41$ & $24.63 \pm 13.69^{* * *}$ & 0.000 \\
\hline
\end{tabular}

Values are presented as mean \pm standard deviation.

Tested by one way ANOVA.

Post-hoc was tested by Tukey's multiple range test $0^{\circ}-+15^{\circ},-15^{\circ}\left({ }^{*} \mathrm{p}<0.05,{ }^{* *} \mathrm{p}<0.01,{ }^{* *} \mathrm{p}<0.001\right)$. 
movements at three different inclination angles of $0^{\circ},+15^{\circ}$, and $-15^{\circ}$. sEMG was performed to measure the activities of five different muscles around the shoulder joint. The biceps brachii, serratus anterior, middle trapezius, and lower trapezius muscles showed increased muscle activity at $-15^{\circ}$, as compared to $0^{\circ}$, however, the upper trapezius did not show any significant increases in muscle activity. Moreover, although there were decreases in values in comparison between $0^{\circ}$ and $+15^{\circ}$, the differences were not statistically significant.

Regarding muscle activity, MVICs of $\leq 20 \%, 21-40 \%$, and $41-60 \%$ indicate low, moderate, and high muscle activity, respectively, while MVIC $>60 \%$ indicates very high muscle activity. ${ }^{25}$ In the study by Martin Pühringe et al. ${ }^{26}$ that compared shoulder muscle activity according to hand grip shape and inclination, the muscles around the shoulder joint showed low or moderate activity when the wall inclination was vertical or negative during therapeutic climbing, based on the report that such movement was appropriate for the initial stage of rehabilitation. Those findings were consistent with the results of the present study.

In the study by Cho et al. ${ }^{27}$ that investigated the changes in the time of muscle onset in the anterior deltoid, posterior deltoid, pectoralis major, and upper trapezius according to body tilting angle during push-up motion, the upper trapezius muscle contracted first at $0^{\circ}$ and $30^{\circ}$, while muscle recruitment appeared in the order of anterior deltoid, posterior deltoid, and pectoralis major. The study reported that to generate a strong force, truncal stabilization was needed before the push-up motion, and as a result, muscles associated with the spine contracted first. In the present study, based on the characteristics of posture and motion associated with hanging on the therapeutic climbing wall, muscle activity in the middle and lower trapezius muscles appeared higher than in the upper trapezius muscle to allow the shoulder to maintain a neutral position and achieve spinal stability, and this appeared at the highest level, an inclination of $-15^{\circ}$.

A study by Shin et al. ${ }^{28}$ that compared muscle activity according to active/passive trunk tilting using a three-dimensional dynamic postural balance exercise machine reported that the muscles were used more optimally in the active mode than in the passive mode, because in the active mode triggered the ability of the user to accurately reach the desired angle and direction and maintain that position, as well as bodily coordination in the sensory nervous system involving the muscular, visual, and vestibular systems. Moreover, during body tilting, the muscles on the side opposite to the direction of tilt are activated, resulting in an interaction between the body position and movement conditions which achieves control over body balance. This can serve as evidence that therapeutic climbing may be a new therapeutic approach that can increase muscle strength and coordination in the sensory nervous system, since it can be used as a tool that promotes active movement by altering wall inclination and causing the user to generate movements according to the existing situation.

In the present study, the muscles around the shoulder were more active at an inclination of $-15^{\circ}$ than $0^{\circ}$, which is believed to be the result of arm muscles being used more than leg muscles during the climbing movement. It is also believed that at an inclination of $+15^{\circ}$, muscle activity in the muscles around the shoulder decreased since a greater percentage of leg muscles were used for climbing. The findings in the present study may be used in future studies to prove various effects of therapeutic climbing, but for now, the findings are expected to be used as reference data to select therapeutic methods in clinical practice.

The limitations in the present study included the small study population, and thus, it would be difficult to generalize the findings. Moreover, the measurements were limited to just three inclination angles, and the study also did not conduct detailed testing on muscle recruitment order and usage rates through simultaneous measurements of the arm and leg muscles. It is believed that future studies should examine muscle activities in different body parts during movements at various inclination angles.

\section{ACKNOWLEDGEMENTS}

This research was supported by the Dongshin University research grants.

\section{REFERENCES}

1. Kim HJ. The effect of strength training on the performance of sports climbing athletes. Chosun University. Dissertion of Master's Degree. 2017.

2. Kohl B. Therapeutisches klettern untersuchung der auswirkungen eines klettertrainings an personen mit rückenschmerze"n, unveröffentliche diplomarbeit an der leopold - franzensuniversität Innsbruck. Psychologie und Sport wissenschaften. 2005.

3. Engbert K, Weber M. The effects of therapeutic climbing in patients with chronic low back pain: a randomized controlled study. Spine. 2011; 
36(11):842-9.

4. Good CR, MacGillivray JD. Traumatic shoulder dislocation in the adolescent athlete: advances in surgical treatment. Curr Opin Pediatr. 2005; 17(1):25-9.

5. Cools AM, Dewitte V, Lanszweert F et al. Rehabilitation of scapular muscle balance: which exercises to prescribe? Am J Sports Med. 2007; 35(10):1744-51.

6. Ludewig PM, Reynolds JF. The association of scapular kinematics and glenohumeral joint pathologies. The J Orthop Sports Phys Ther. 2009; 39(2):90-104.

7. Bae SS, Kim BJ, Lee KH. A study of muscle imbalance of head, cervical and shoulder region. J Kor Phys Ther. 2001;13(3):769-76.

8. Bae SS, Choi JW, Chung HA et al. Biomechanical analysis of scapular pattern in proprioceptive neuromuscular facilitation. J Kor Phys Ther. 1999;11(3):65-9.

9. Cools AM, Struyf F, De MK et al. Rehabilitation of scapular dyskinesis: from the office worker to the elite overhead athlete. Br J Sports Med. 2014;48(8):692-7.

10. Ellenbecker TS, Cools A. Rehabilitation of shoulder impingement syndrome and rotator cuff injuries: an evidence-based review. Br J Sports Med. 2010;44(5):319-27.

11. Wilk K, Reinold MM, Dugas JR et al. Current concepts in the recognition and treatment of superior labral (slap) lesions. J Orthop Sports Phys Ther. 2005;35(5):273-91.

12. Pühringer M, Strutzenberger G, Leitl D et al. Possibilities of altering arm and shoulder muscle activation in a static therapeutic climbing exercise through arm position, hand support and wall inclination. Eur J Sport Sci. 2017;17(9):1212-9.

13. Park BJ, Kim JH, Kim JH et al. Comparative analysis of trunk muscle activities in climbing of during upright climbing at different inclination angles. J Phys Ther Sci. 2015;27(10):3137-9.

14. Grzybowski C, Donath L, Wagner H. Association between trunk muscle activation and wall inclination during various static climbing positions: implications for therapeutic climbing. Sportverletzung Sportschaden. 2014;28(2):75-84.

15. Rene Kittel. Therapeutisches klettern das praxisbuch. Bad Feilnbach. 2015;58-9.

16. Kim SC. The effect of strengthening exercise of trapezius and serratus anterior on pain and muscle activation for spinal cord injury patients with functional shoulder impingement syndrome. Yong-In University. Dissertion of Master's Degree. 2012.

17. Soderberg GL, Knutson LM. A guide for use and interpretation of kinesiologic electromyographic data. Phys Ther. 2000;80(5):485-98.

18. Cram JR, Kasman GS, Holtz J. Introduction to surface electromyography. Maryland, Aspen. 1998.

19. Bjelle A. Epidemiology of shoulder problems. Baillieres Clin Rheumatol. 1989;3(3):437-51.

19. Lim WS. The effects of scapular pattern and hold-relax technique of pnf on the rom and vas in frozen shoulder patients. Daegu university. Dissersion of Master's Degree. 2002.

20. Kwag KI, Seo EK, Kim TY. The effects of group exercise, manual therapy and home exercise on pain, range of motion and function in patient with adhesive capsulitis. J Kor Phys Ther. 2016;28(2):101-5.

21. Lee MH, Park RJ. The effects of taping therapy on the rom and vas in adhesive capsulitis. J Kor Phys Ther. 2003;15(3):223-38.

22. Muehlbauer T, Stuerchler M, Granacher U. Effects of climbing on core strength and mobility in adults. Int J Sports Med. 2012;33(6):445-51.

23. Buechter RB, Fechtelpeter D. Climbing for preventing and treating health problems: a systematic review of randomized controlled trials. Ger Med Sci. 2011;9:1-9.

24. Grzybowski C, Eils E. Therapeutic climbing - barely explored but widely used. Sportverletzung Sportschaden. 2011;25(2):87-92

25. Tucci HT, Ciol MA, de Araújo RC et al. Activation of selected shoulder muscles during unilateral wall and bench press tasks under submaximal isometric effort. J Orthop Sports Phys Ther. 2011;41(7):520-5.

26. Pühringer M, Strutzenberger G, Leitl D et al. Possibilities of altering arm and shoulder muscle activation in a static therapeutic climbing exercise through arm position, hand support and wall inclination. Eur J Sport Sci. 2017;17(9):1212-9.

27. Cho YH, Kim SO, Choi JH. The differences of shoulder muscle activity onset time according to body tilting angle in push-up exercise. J Korean Soc Phys Med. 2015;10(2):175-81.

28. Shin SH, Yu M, Jeong GY et al. The assessment on electromyography of trunk muscle according to passive and active trunk tilt exercise of 3-d dynamic postural balance training system. J Korean Soc Precis Eng. 2013;30(3):331-9. 